\title{
Schirmer Test Wetting
}

National Cancer Institute

\section{Source}

National Cancer Institute. Schirmer Test Wetting. NCI Thesaurus. Code C75526.

A test used to determine the amount of tears collected on a filter paper strip in 5 minutes. 